$\left(\mathrm{AgNO}_{3}\right.$ dissolved in $\mathrm{RbNO}_{3}$ and in $\left.\mathrm{CsNO}_{3}\right)$ are generally interpreted as an indication of "complex ions" (which is another way of saying that a simple model with only three ionic species is inadequate). The small absolute value of $r_{12}$ in the $\mathrm{AgNO}_{3}-\mathrm{KNO}_{3}$ mixture makes the experimental uncertainty more important. Thus the positive value at $380{ }^{\circ} \mathrm{C}$ indicates that also the value at $340{ }^{\circ} \mathrm{C}$ should be (small and) positive (since increased temperature should lead to increased "dissociation").
The present investigation shows that dissolving small amounts of silver nitrate in lithium, sodium, and potassium nitrates creates mixtures with a very simple structure (a melt consisting of only three ionic species) while there is evidence of "complex ions" when silver nitrate is dissolved in rubidium and cesium nitrates.

The authors are indebted to Dr. Arnold LundÉn for his kind interest in this work. It has been financially suported by Åke Wibergs Stiftelse.

\title{
The Temperature Dependence of the Isotope Effect for Electromigration of Potassium Ions in Molten Potassium Nitrate
}

\author{
Arnold Lundén and Alf Ekhed \\ Department of Physics, Chalmers Institute of Technology, Göteborg, Sweden
}

(Z. Naturforsch. 23 a, 1779—1782 [1968] ; received 8 August 1968)

\begin{abstract}
The relative difference $(\Delta b / b)$ between the electromigration mobilities of ${ }^{39} \mathrm{~K}$ and ${ }^{41} \mathrm{~K}$ in molten $\mathrm{KNO}_{3}$ has been measured over the range $354^{\circ}$ to $586^{\circ} \mathrm{C}$. The mass effect, $\mu=(\Delta b / b) /(\Delta m / m)$, becomes larger when the temperature is increased, following the relation

$$
-\mu=0.0385+0.000124(t-337)
$$

where $t$ is the temperature in ${ }^{\circ} \mathrm{C}$. Due to thermal decomposition, the nitrate is partly converted to nitrite, but it is proved by performing experiments with different initial concentrations of nitrite, that the isotope effect for potassium is not influenced noticeably by the concentration of the anions.

The experiment is designed to give an enrichment of the heavy isotope ${ }^{41} \mathrm{~K}$ in a small anode compartment and in the upper part of the separation tube. However, it was possible to establish that a slight, but significant, enrichment of the light isotope ${ }^{39} \mathrm{~K}$ was obtained in the lower part of the separation tube, i. e. just above the opening into the large cathode compartment. A separation factor of 1.003 was estimated for this enrichment effect, which is due to non-ideal conditions of the experiment.
\end{abstract}

13 years ago we reported that we had studied the isotope effect for electromigration of potassium ions in molten potassium nitrate ${ }^{1}$, and similar measurements have been made recently by ОKADA ${ }^{2}$. In recent years the temperature dependence of the isotope effect has achieved considerable interest ${ }^{3}$, halides and sulfates being considered so far. As a first part of an investigation of the influence of temperature and concentration on isotope effects in molten nitrates, we can now report the results of experiments with pure $\mathrm{KNO}_{3}$ as well as with mixtures of $\mathrm{KNO}_{3}$ and $\mathrm{KNO}_{2}$.

\section{Experimental}

The experimental arrangement is essentially the same as previously ${ }^{1}$, i. e. a separation column (length

1 A. Lundén, C. Reuterswärd, and N. SJöberg, Z. Naturforsch. 10 a, 279 [1955].

2 I. OKaDA, Thesis, Tokyo 1966.
$20 \mathrm{~cm}$, inner diam. about $4 \mathrm{~mm}$ ) separates a small compartment at the anode from a large compartment on the cathode side. To prevent liberation of alkali metal an excess of gas (either a mixture of $\mathrm{NO}_{2}$ and $\mathrm{O}_{2}$ or only $\mathrm{NO}_{2}$, see discussion below) is bubbled through the aluminium cathode. The duration of the first experiments was 6 to 10 days, but due to increased accuracy of our mass spectrometer, it became possible to reduce the duration to 1 to 2 days. As usual, we worked with a very simple furnace made of two concentric glass tubes ${ }^{4}$. This arrangement allows us to observe the whole cell all the time, but a disadvantage is that considerable temperature differences are obtained in the furnace. For this reason we fitted three thermocouples onto the cell, sitting at the same height as the bottom, middle and top of the separation column.

In the chemical analysis of the samples we determined the total amount of anions, and the concentrations

\footnotetext{
3 A. Klemm (Ed. W. Spindel), Advan. Chem. Ser. in press.

4 A. LundÉn, Thesis, Göteborg 1956, p. 38.
} 


\begin{tabular}{|c|c|c|c|c|c|c|}
\hline Exp. & $\underset{{ }^{\circ} \mathrm{C}}{\text { Temp. }}$ & $\begin{array}{l}\text { Duration } \\
\text { hours }\end{array}$ & $\begin{array}{c}\text { Transp. } \\
\text { charge } \\
\text { Ah }\end{array}$ & $\begin{array}{l}\text { Mass effect }(-\mu) \\
\text { for each analysis }\end{array}$ & $\begin{array}{c}\text { Chosen } \\
\text { value }\end{array}$ & Remark \\
\hline 1 & $360 \mathrm{a}$ & 145.5 & 14.6 & 0.037 & 0.037 & Published 12 \\
\hline 2 & 360 a & 149.5 & 13.1 & 0.038 & 0.038 & \\
\hline 3 & $360 \mathrm{a}$ & 248.0 & 23.7 & 0.038 & 0.038 & \\
\hline 4 & 354 & 29.0 & 6.76 & $0.044 ; 0.044$ & 0.044 & \\
\hline 5 & 370 & 47.8 & 9.83 & $0.043 ; 0.042$ & 0.042 & \\
\hline 6 & 375 a & 46.5 & 9.38 & $0.024 ; 0.034$ & 0.034 & \\
\hline 7 & 388 & 24.0 & 4.94 & $0.046 ; 0.052 ; 0.052$ & 0.050 & \\
\hline 8 & 442 & 35.7 & 7.09 & $0.047 ; 0.045$ & 0.046 & $79 \% \mathrm{KNO}_{2}$ at start \\
\hline 9 & 454 & 32.1 & 7.11 & $0.048 ; 0.044$ & 0.046 & \\
\hline 10 & $470 \mathrm{a}$ & 57.0 & 11.4 & $0.055 ; 0.061$ & 0.058 & $100 \% \mathrm{KNO}_{2}$ at start \\
\hline 11 & 496 a & 41.6 & 8.00 & $0.059 ; 0.055$ & 0.057 & $100 \% \mathrm{KNO}_{2}$ at start \\
\hline 12 & 541 & 28.0 & 5.61 & $0.098 ; 0.069 ; 0.071$ & 0.070 & \\
\hline 13 & 562 & 23.3 & 3.75 & $0.059 ; 0.071$ & 0.065 & \\
\hline 14 & 586 & 30.0 & 6.83 & $0.071 ; 0.068$ & 0.070 & \\
\hline
\end{tabular}

Table 1. Data of experiments, and results. a Temperature was measured at only one position in the furnace.

of nitrite, oxide and sodium. The sodium analysis was done by atomic absorption spectrophotometry. For the first experiments the mass analysis could only be done once, but thanks to improvements of the capacity of our mass spectrometer, it became possible to make two, or in some cases three, independent series of mass analysis for each experiment. (The importance of this for the evaluation of isotope enrichment experiments has been discussed previously ${ }^{5}$.) The results of the experiments are summarized in Table 1.

\section{Influence of Anions on the Isotope Effect}

The thermal decomposition of molten nitrates has been studied by several authors, e.g. Freeman ${ }^{6}$, while others, e. g. Arvia and coworkers ${ }^{7,8}$ have studied electrode reactions in molten nitrates and nitrites. We could expect that both nitrate and nitrite would be present as anions in our experiments, and the chemical analysis showed that this was indeed the case. For the experiments at the highest temperatures (no 13 and 14) the concentration of $\mathrm{KNO}_{2}$ was found to be of the order of $25-30$ mole per cent in the main part of the cell (cathode compartment and separation tube) while it was only about $4 \%$ in the anode compartment. On the other hand for the experiment at the lowest temperature (no 4) the nitrite content was very low in both compartments and of the order of $1-2 \%$ in the separation tube. Since it was obvious that the concentration of nitrite depended on the temperature at which the experiment was performed, it was necessary to check whether the choice of anion in-

5 A. LundÉn and V. Luubimov, Z. Naturforsch., in press.

${ }^{6}$ E. S. Freeman, J. Am. Chem. Soc. 79, 838 [1957].

7 W. E. Triaca and A. J. Arvia, Electrochim. Acta 9, 1055 [1964]. fluenced the mass effect. For this reason a couple of experiments were made either with pure $\mathrm{KNO}_{2}$ as initial salt (no 10 and 11) or with a mixture of $\mathrm{KNO}_{2}$ and $\mathrm{KNO}_{3}$ (no 8). In addition to these experiments which were run for the normal time and analysed completely, we also made some experiments of short duration, which were analysed only chemically. The analysis of these experiments with a high initial content of $\mathrm{KNO}_{2}(43-100 \%)$ proved that the oxidation of nitrite to nitrate was rapid both at the platinum anode and at the aluminium cathode, through which pure $\mathrm{NO}_{2}$ was bubbled. It was thus not necessary to have a mixture of $\mathrm{NO}_{2}$ and $\mathrm{O}_{2}$ in order to obtain nitrate at the cathode. For this reason the gas mixture was used only for experiments $1-3,6,9$ and 12 , while pure $\mathrm{NO}_{2}$ was used for the other ones.

There is no obvious correlation between the mass effect and the initial concentration of nitrite in the melt, and we conclude that the isotope effect of electromigration is about the same whether the anions are nitrate or nitrite ions. OKADA reports experiments with pure $\mathrm{KNO}_{3}$ as well as with $\mathrm{KNO}_{3}-\mathrm{K}_{2} \mathrm{SO}_{4}$ mixtures ${ }^{2}$, and there was no significant difference between the isotope effect in these two cases. However, it is well-known from comparisons between different halides, that the anion has an influence on the mass effect for the cation, and for all alkali nitrates investigated so far, the mass effect is lower than for the corresponding halides, c. f. cit. ${ }^{9}$.

8 A. J. Calandra and A. J. Arvia, Electrochim. Acta 11, 1173 [1966].

9 S. Jordan and A. Klemm, Z. Naturforsch. 21 a, 1584 [1966]. 
OKada also made some experiments with an inorganic cation exchanger (zirconyl phosphate) as packing in the separation tube, and the isotope effect was the same as with an inert packing (quartz) ${ }^{2}$. In our early experiments (no $1-3$ ) the tubes were packed with quartz, later on we have used Pyrex (no 4-8) or Supremax glass (no 9-14) for the cell as well as for the packing. A certain corrosion of the glass takes place, and as a result a few per cent of $\mathrm{Na}$ could be detected in the samples from our separation tubes. It is reasonable to assume that a corresponding amount of potassium can have entered the glass, and a correction should be made for this loss of potassium salt when the mass effect is calculated. As the amount of sodium increases in the melt, an increasing fraction of the charge transport is due to $\mathrm{Na}^{+}$ions, and one should need to know the transport number for this cation in order to make corrections in the calculations. It is not possible in practice to determine the relative mobility of $\mathrm{Na}^{+}$and $\mathrm{K}^{+}$ions from the present experiments, but a rough estimate indicates that they do not differ much at these low concentrations of $\mathrm{Na}^{+}$. Although it thus is uncertain how the corrosion reaction influences the evaluation of the experiments, calculations under different assumptions show that the error corrosion introduces into our mass effects probably does not exceed 2 or 3 per cent in any of the present experiments.

\section{Evidence for Anomalies in the Isotope Distribution}

The expected distribution of the potassium isotopes in the separation tube can be calculated by solving the differential equations under the proper boundary conditions ${ }^{\mathbf{1 0}}$. For experiments of a rather short duration done with separation tubes of a sufficient length, we can expect for ideal conditions that the concentration of ${ }^{41} \mathrm{~K}$ decreases gradually in the separation tube as the distance from the anode compartment is increased, until the normal concentration is obtained, and that the concentration in the rest of the tube is the same as in the cathode compartment. In practice, the smoothness of the obtained distribution is limited by the precision of the mass analysis. However, for the experiments reported here, as well as for other electromigration experiments done in our laboratory, it has now and then been reason to ask - for the part of the tube where a change in isotope abundances was expected, as well as for the part where the composion should remain unaltered - whether the obtained deviations from the composition that should correspond to ideal conditions, could in part be real, and not entirely due to the randomness of the mass analyses. In order to verify deviations that are of the same order as the standard deviation of a single mass analysis, a number of repeated measurements would be required. With the capacity of our laboratory it is not practical to measure through the whole series of samples from a certain experiment more than twice. (A third measurement was done for two experiments, where the mass effects calculated from the two first series disagreed more than a few per cent.) Thus, it is not possible to repeat the mass analysis of a single experiment so many times as would be needed to see if the abundance distribution has irregularities in the part of the column where an enrichment has taken place. The situation is easier for the part of the cell where we expect that the normal composition has been maintained; this usually corresponds to several samples from the lower part of the separation tube and from the cathode compartment. For the present investigation we can now consider eight cells for which the whole column as well as the cathode compartment were analysed twice or thrice. (For the other cells some samples were omitted in at least one of the analyses.) Regarding the highest content of ${ }^{39} \mathrm{~K}$, we find the following:

A) Of the six cells that were analysed twice

4 cells have the maximum at the same position both times, and, in addition, for three of these, also the second highest content of ${ }^{39} \mathrm{~K}$ comes at the same position;

1 cell has the order of the maximum and the second highest abundance reversed between the two analyses;

1 cell has a sample that gives the maximum once, but only the second highest abundance the other time;

B) Of the two cells that were analysed three times

1 cell has the maximum at the same position all three times, and

1 cell has it two times of three.

10 For a summary of the results for different cases see e. g. ref. ${ }^{4}$, p. 26. 
Also other details of the distrtibution within a cell tended to repeat. Probability estimations prove that these observations cannot be due to randomness, and the existence of a non-ideal distribution is verified for the present experiments. There is evidence for similar phenomena occurring also in experiments with other systems, and the probable cause will be discussed elsewhere ${ }^{11}$.

For most of our cells the maximum abundance of ${ }^{39} \mathrm{~K}$ is found either in the sample from the bottom part of the tube or in the one just above that. For all the series of analyses that cover the whole tube, we have compared the abundance ratio measured for the lowest sample with the calculated normal composition (i. e. the average composition of several samples) as well as with the abundance ratio measured for the salt from the cathode compartment. For the first-mentioned comparison, we find in 19 cases of 22 that the concentration of ${ }^{39} \mathrm{~K}$ was higher than normal in the bottom sample, and (averaged over the 22 measurements) the separation factor becomes $1.0030 \pm 0.007$. (The standard deviation of the mean is quoted as the error.) For the second comparison, in 16 cases of 18 , the measured ${ }^{39} \mathrm{~K}$ abundance was higher in the bottom sample than in the cathode compartment, and averaging gives the separation factor $1.0034 \pm 0.0009$. Thus, whether we compare with the calculated normal composition or with the cathode compartment, there is a slight, but significant enrichment of ${ }^{39} \mathrm{~K}$ in a part of the separation tube.

\section{Temperature Dependence of the Mass Effect}

As discussed above, a slight enrichment of ${ }^{39} \mathrm{~K}$ can build up in the lower part of the separation tube. This is of importance for the calculation of the mass effect for two reasons. Firstly, we have the problem of which samples that should be considered when the "normal composition" is evaluated. Secondly, the region on the anode side where ${ }^{41} \mathrm{~K}$ is enriched will after some time get into contact with the region where there is a slight enrichment of ${ }^{39} \mathrm{~K}$, and the basic assumption, that we have the normal composition at the end of the region with an enrichment of ${ }^{41} \mathrm{~K}$, is no longer valid. By

\footnotetext{
11 A. LundÉn, Z. Naturforsch. in press.

${ }^{12}$ In the original publication ${ }^{1}$ the mass $m=39.1$ was used when the mass effect is calculated, while the value quoted here corresponds to the normal practice, according to which $m=40$ is used. In the original evaluation of this experiment
}

using a computer we could evaluate each series of mass analysis under different assumptions regarding the normal composition and also for different interpretations of the chemical analysis, cf. above and cit. ${ }^{5}$. This gives a good check of the accuracy of the mass effects. As seen from Table 1, where we have listed the value of the mass effect selected for each series of mass analyses, the agreement is usually quite good between the series for a certain experiment. After excluding two extreme values of $\mu$ (the lowest one for no 6 and the highest one for no 12), the following linear relationship was computed for experiments $4-14$ :

$$
\begin{aligned}
-\mu= & (0.0385 \pm 0.0012) \\
& \cdot[1+(0.00324 \pm 0.00039)(t-337)]
\end{aligned}
$$

for $354 \leqq t \leqq 586{ }^{\circ} \mathrm{C}$.

The errors are standard deviations. An alternative way to express the temperature dependence is to estimate $\partial \ln \mu / \partial \ln T$, where $T=t+273$. At $400{ }^{\circ} \mathrm{C}$ this quotient becomes 1.81 for $\mathrm{KNO}_{3}$, while it is 1.22 for $\mathrm{K}^{+}$in $\mathrm{KCl}$ at $850{ }^{\circ} \mathrm{C}^{9}$.

The three experiments of long duration, no $1-3$, give mass effects that are about $9 \%$ lower than what Eq. (1) gives for $360^{\circ} \mathrm{C}^{12}$. A comparison is uncertain, since the temperature was not measured as accurately in the first experiments as was done later on, but one might conclude that experiments of an extended duration in general give fairly good information on mass effects in spite of possible disturbances due to non-ideal behaviour of the separation tube or other causes. ОкаDA, who made his experiments with pure $\mathrm{KNO}_{3}$ at $380{ }^{\circ} \mathrm{C}$ with a duration of 100 to 177.5 hours obtains a mass effect of 0.041 , which fits quite well with our results.

The interpretation of the unusually great dependence of the mass effect upon temperature thus found for $\mathrm{K}^{+}$in $\mathrm{KNO}_{3}$ will be discussed in connection with the results for other nitrates.

This investigation is supported by "Statens naturvetenskapliga forskningsråd" and "Magn. Bergvalls stiftelse". We are indebted to Mr. Manne Lövenby for performing the measurements with the mass spectrometer and to Mrs. Ulla Blume and Miss AnN-CharLOTTE Jönsson for the chemical analyses.

it was assumed that the region with an enrichment of ${ }^{41} \mathrm{~K}$ covered $10 \mathrm{~cm}$ of the tube. If we instead assume that the region with an enrichment was about $15 \mathrm{~cm}$, a recalculation gives a mass effect of 0.039 for this experiment. 